\title{
Georges Bertrand e a Análise Integrada da Paisagem em Geografia
}

\author{
Georges Bertrand and the Integrated Landscape Analysis in Geography
}

\author{
BERNARDINO $^{1}$, D. S. M.; OLIVEIRA ${ }^{2}$, A. M.; DINIZ ${ }^{3}$, M. T. M.
}

diogo-bernardino@hotmail.com

\begin{abstract}
Resumo
No sentido de colaborar com o conhecimento sobre a análise da paisagem em Geografia, propõe-se, aqui, um artigo de revisão bibliográfica que trate, de maneira crítica e analítica, das contribuições teóricometodológicas de Georges Bertrand para essa temática. Esse autor, em 1968, no contexto de renovação da Geografia e de desenvolvimento progressivo de sínteses naturalistas mais rebuscadas, concebeu a Análise Integrada da Paisagem (Paisagem e Geografia Física Global; Teoria Geossistêmica Bertrandiana) amplamente difundida na Geografia brasileira. No presente trabalho, busca-se abordar o contexto históricocientífico dessa teoria, os seus conceitos-chave, sua singularidade perante sínteses naturalistas similares, a metodologia proposta e as principais críticas e proposições a ela direcionadas. Expecta-se que o referido trabalho - de cunho panorâmico - favoreça a inserção dessas concepções nas novas gerações acadêmicas de Geografia.
\end{abstract}

\begin{abstract}
In order to collaborate with the knowledge about the landscape analysis in Geography, it is proposed here an article of bibliographical revision that deals, in a critical and analytical way, with the theoretical-methodological contributions of Georges Bertrand to this theme. In 1968, in the context of the renewal of Geography and the progressive development of more elaborate naturalistic syntheses, this author conceived the Integrated Landscape Analysis (Landscape and Global Physical Geography, Bertrandian Geosistemic Theory) - widely diffused in Brazilian Geography. In the present work, we seek to approach the historical-scientific context of this theory, its key concepts, its singularity before similar naturalistic syntheses, the proposed methodology and the main criticisms and propositions addressed to it. It is expected that this work - of a panoramic nature - will favor the insertion of these conceptions in the new academic generations of Geography.
\end{abstract}

Palavras-chave: Análise Integrada da Paisagem. Bertrand. Paisagem e Geografia Física Global.
Keywords: Integrated Analysis of Landscape. Bertrand. Landscape and Global Physical Geography.

\section{INTRODUÇÃO}

O progressivo desenvolvimento da concepção de existência de uma organização natural da superfície terrestre que se estabelece a partir da inter-relação de seus elementos internos (rochas, solos, seres vivos, água, etc.) e externos (sol, movimentos orbitais, atividade interna do planeta) promoveu uma série de formulações teórico-metodológicas nas ciências naturais e na Geografia (Física).

Segundo Cavalcanti e Corrêa (2014), diversas foram, no século XX, as tentativas metodológicas ("sínteses naturalistas”) criadas para se compreender, nessa concepção holística, a superfície terrestre: Estudo de Geossistemas, Análise Integrada da Paisagem, Geografia Ecológica, Biogeografia Ecológica, Modelo Ecorregional, Biomas, Biogeocenoses e Complexos Biogeocenóticos, Land Systems, etc.; cada uma assumiu um termo diferente para o seu objeto de 
estudos: a superfície terrestre hierarquizada ${ }^{1}$ (paisagem, ecossistema, geossistema, região natural, unidades de paisagem e similares).

Georges Bertrand (*1932), geógrafo francês, foi responsável pela concepção da Análise Integrada da Paisagem ${ }^{2}$. Esta estabeleceu-se como um dos grandes vieses do movimento de renovação da Geografia do Século XX (MORAES, 1994). Em conformidade com o caráter sistêmico da Geografia Pragmática, tratava de uma metodologia geográfica global (integrada interdisciplinarmente) para a análise da paisagem - a partir da aplicação da Teoria Geral dos Sistemas de Bertalanffy —, considerando a ação antrópica como parte integrante desse complexo (MENDOZA; JIMÉNEZ; CANTEIRO, 2002).

$\mathrm{O}$ artigo "Paysage et géographie physique globale: Esquisse méthodologique" de Bertrand (1968) foi um marco para a Geografia Física Ocidental, uma vez que, neste, foi esboçada a referida metodologia, que era considerada aplicável, do ponto de vista prático, para o estudo da paisagem (DINIZ; OLIVERA; BERNARDINO, 2015). Traduzido para, pelo menos, o Inglês, o Português e o Espanhol, este trabalho influenciou grandes nomes da Geografia Física na Espanha e no Brasil, como Maria Bolós, Ab’Saber, Christofoletti, etc.; foi base metodológica para os zoneamentos agroecológicos do Nordeste Brasileiro, além de ter se difundido para todos os cursos de Geografia do Brasil (CAVALCANTI, 2013).

Sua expressividade nos estudos de Geografia (Física), como visto, é facilmente identificável. O que torna bastante pertinente a realização de estudos que a tenham como foco, a exemplo de artigos e demais manuscritos de revisão bibliográfica. Nesse sentido, sabendo que trabalhos de cunho revisional têm demasiada importância na construção e desenvolvimento da ciência, pois assumem uma função de síntese do conhecimento, de catalogação e de reunião de escritos de uma determinada abordagem para a transferência de conhecimento entre o cientista e os pares (FIGUEIREDO, 1990), objetiva-se com este ensaio resgatar a síntese naturalista proposta por

\footnotetext{
1 Cavalcanti (2013) e Cavalcanti e Corrêa (2014) perceberam que todas essas propostas teórico-metodológicas sínteses naturalistas - comungam, genericamente, de um mesmo objeto de estudos, as áreas naturais, que nada mais são que a própria superfície terrestre hierarquizada: "produto das relações entre os componentes da natureza de modo a formar um todo autônomo do ponto de vista funcional. Este conceito recebe nomenclaturas diversas ao longo da história, revelando nuances em termos de orientação metodológica" (CAVALCANTI; CORRÊA, 2014, p. 381, grifo dos autores).

2 Esta é uma denominação genérica considerada pelos autores deste artigo para se referirem à proposta teóricometodológica de Bertrand (1968). Pois, nessa obra, o geógrafo francês, por somente está traçando um esboço metodológico, não se preocupou em nomeá-lo. Portanto, a opção dos autores se dá em virtude de considerar inapropriado o título — demasiadamente utilizado - "Teoria Geossistêmica", uma vez que Georges B. ainda não havia creditado o geossistema como totalidade, uniformizando, assim, com as concepções de Sotchava (1977); "geossistema" era somente o nome de uma unidade taxonômica. Por fim, o nome "Análise Integrada da Paisagem" justifica-se por parafrasear (sinônimo) o título e a intenção da obra de Bertrand, uma vez que, nesta, foi proposta uma metodologia de análise global (integrada) da paisagem: "Paisagem e Geografia Física Global: Esboço metodológico".
} 
Georges Bertrand, a fim de produzir material de caráter introdutório e panorâmico para inserção de suas concepções nas novas gerações acadêmicas de geografia.

Para tanto, buscou-se abordar o contexto histórico-científico dessa teoria, os seus conceitoschave, a sua singularidade perante sínteses naturalistas $(\mathrm{SN})$ similares (como o Estudo de Geossistema de Sotchava), seu conteúdo (isto é, a metodologia proposta em si: taxonomia, dinâmica, tipologia e cartografia das paisagens) e as principais críticas e proposições direcionadas. Para que, assim, o referido trabalho promova uma contribuição científica no que diz respeito ao conhecimento elementar da Geografia Bertrandiana.

\section{SOBRE OS CONTEXTOS HISTÓRICO, FILOSÓFICO, CIENTÍFICO E TEÓRICO DA ANÁLISE INTEGRADA DA PAISAGEM DE GEORGES BERTRAND}

As concepções de Georges Bertrand acerca da análise da paisagem representam um produto inacabado de influências científicas, sociais, econômicas, filosóficas, etc. Ao analisar a envergadura contextual que levou Georges Bertrand a conceber suas formulações teóricometodológicas, percebe-se que esse cenário se estabeleceu de forma cumulativa, a partir das várias influências que se anexaram ao fluxo de desenvolvimento da Geografia. Aqueles acontecimentos que promoveram, direta ou indiretamente, uma relativa holisticidade aos estudos da Geografia, são os mais relevantes para suas concepções. Nesse item, traçamos algumas dessas influências profundas e imediatas - do pensamento Bertrandiano.

\section{As sínteses naturalistas}

Inicialmente, pode-se tratar do desenvolvimento de sínteses naturalistas - que se constituiu de forma gradual/profunda - como uma sequência de perspectivas que deram base ideológica para a própria síntese naturalista Bertrandiana.

As sínteses naturalistas são concepções teórico-metodológicas que buscam uma visão integrada da natureza na superfície terrestre, derivada das relações entre os componentes naturais. Assim, revelam uma preocupação em sistematizar o estudo das interações complexas entre os diversos componentes da natureza e de realizar sua classificação a partir de sua diferenciação, uma vez que se apresentam em tridimensionalidade, sendo passíveis de delimitação (CAVALCANTI, 2013). Segundo Cavalcanti e Corrêa (2014), as sínteses naturalistas são desenvolvidas, embrionariamente, desde a antiguidade. No entanto, para este artigo, reputa-se necessário dar enfoque apenas aos trabalhos do século XIX em diante, a partir de Humboldt (1769-1859) e 
Dokuchaev (1846-1903), uma vez que representam SN mais rebuscadas, e que influenciaram mais diretamente as concepções Bertrandianas,

Sobre esses dois naturalistas - Humboldt e Dokuchaev —, é possível afirmar que ambos seguiram numa contra-corrente à especialização das ciências, que estava assentada no paradigma newtoniano-cartesiano (reducionista) e que havia sido reafirmada pelo Iluminismo. Pois, uma ideia de unidade - natural - fomentava suas buscas pela compreensão das relações entre os fenômenos terrestres. Esses cientistas embasavam seus pensamentos nas diversas experiências que tiveram ao longo do globo terrestre, por efeito das suas inúmeras excursões naturalistas - especialmente Humboldt (CAVALCANTI; CORRÊA, 2014).

Essas várias expedições naturalistas de Humboldt culminaram na montagem de uma vasta coleção de dados e informações sobre diversas regiões. Isso tornou possível sua proposta de zonalidade, que trata do controle exercido pela altitude e latitude na distribuição dos elementos naturais, como clima, vegetação e fauna - considerações que embasaram afirmações de Darwin, quanto à evolução das espécies, de Walter, sobre os Biomas, e do próprio Dokuchaev, na Teoria de Zonas Naturais (CAVALCANTI; CORRÊA, 2014). Nesta última, uma proposição de zonas naturais para o hemisfério norte, sugere-se uma diferenciação das zonas pelo clima, relevo, fauna e vegetação, que estariam sintetizados no solo. Assim, o solo seria o resultado da interação de todos esses componentes naturais.

Em comum, Dokuchaev e Humboldt apelavam por uma visão inteira do mundo e afirmavam que tão importante quanto os estudos especializados, era a árdua compreensão da unidade formada pela relação entre os distintos componentes da natureza. Essas ideias, como aponta Cavalcanti (2013), deram vazão ao surgimento de muitas novas áreas de estudo, como a Geoquímica da Paisagem de Boris B. Polinov, a Biogeoquímica e a Teoria da Biosfera de Vladimir I. Vernadsky, a Bigeocenologia de Vladimir N. Sukachev e a Ciência da Paisagem de Lev S. Berg. Na geografia, a pioneira repercussão foi o Estudo de Geossistemas (ou Teoria dos Geossistemas) de Sotchava e, posteriormente, a Ecodinâmica de Tricart, por sua vez, ambas influenciaram a Geografia Física Global (1968).

No entanto, antes de partir para a abordagem dessas três concepções geográficas, é necessário contextualizá-las — além dos processos graduais/profundos - nas intensas/imediatas transformações econômicas, sociais, políticas, filosóficas, científicas e tecnológicas que atingiram, de maneira retroalimentar entre si, o século XX, especialmente na sua segunda metade - período em que foram elaboradas tais teorias. 


\section{As incertezas na compreensão de uma realidade modificada}

Desde o início do século XX, em razão das descobertas da Física Quântica e da elaboração da teoria da relatividade, de Albert Einstein, novas concepções acerca da matéria, do espaço e do tempo e do próprio universo surgem, superando princípios, conceitos e métodos da ciência tradicional (NASCIMENTO, 2003), o que trouxe um quadro de incertezas para a ciência. Como mencionam Ferreira e Simões (1986), os paradigmas positivistas foram seriamente perturbados, porque surgiram novos parâmetros para se analisar a realidade. Além disso, a própria realidade se mostrava diferente, complexizada pelas modificações que estivera passando (MORAES, 1994).

A respeito dessas intensas transformações do século XX, é possível citar a consolidação do sistema capitalista como um importante vetor de dinamicidade e instabilidade social e política. Com esse sistema econômico, o mundo havia se diferenciado rapidamente desde o reducionismo cartesiano e o positivismo clássico: a realidade era, agora, a das empresas multinacionais, do rápido desenvolvimento industrial, da mecanização da agricultura, do êxodo rural, da urbanização e dos problemas de ordem ambiental (etc.). Contemporâneo a isso, no âmbito político-econômico, se dava o fim da II Guerra Mundial, o início da guerra fria, com a corrida espacial, e o surgimento de grandes movimentos sociais: de direitos civis, estudantis, sindicais, artísticos, feministas, hippies e ambientalistas (MENDOZA; JIMÉNEZ; CANTEIRO, 2002). Tudo isso repercutiu de forma direta nas bases filosóficas e científicas do século XX, de modo a serem repensadas, do ponto de vista da aplicabilidade, ainda nesse século.

\section{A intencionalidade dos novos paradigmas filosófico-científicos}

Contingências políticas, sociais, econômicas e ambientais promoveram pressão para uma necessidade de incorporar a ciência aos seus contextos, seja no sentido de essa dar apoio técnico ao avanço e modernização do capitalismo ou na intenção de procurar soluções para os avantajados problemas do mundo desenvolvido (MORAES, 1994). É assim que surgem os grandes trabalhos de cunho técnico, que denotavam a atuação do Estado e o nascimento dos ideais conservacionistas, como ordenamento territorial, planejamento agropecuário, manejo florestal, etc. Além de um amplo desenvolvimento tecnológico, foi necessária toda uma alteração dos fundamentos fílosóficos clássicos, que, diante da complexização da realidade, haviam ruído, assim como os métodos científicos e os respectivos procedimentos técnico-metodológicos (DINIZ; OLIVEIRA; BERNARDINO, 2015). 
Em face disso, novas bases filosóficas emergiram para suceder os postulados do Positivismo Clássico, como no caso do Positivismo Lógico (ou Neopositivismo), surgido no Círculo de Viena. Nesse novo assentamento filosófico foi proposto uma superação do indutivismo puro, adotando-se o uso da lógica (somada ao empirismo), da estatística e de uma linguagem comum para as ciências (MORAES, 1994). Admitiu-se, agora, além da reducionista/analítica, uma abordagem sistêmica. Isso permitiu uma alternativa científica ao paradigma newtoniano-cartesiano, que era mecanicista e apregoava uma fragmentação do conhecimento para a compreensão do todo. Nessa nova perspectiva, passou-se a fazer uso do paradigma holístico (ou Complexo), pelo qual se apreende a realidade enquanto um organismo interconectado, não-linear, isto é, um sistema complexo: um conjunto organizado de elementos, entre os quais há interações, troca de energia, matéria e informação (CHRISTOFOLETTI, 1999).

\section{A incorporação do holismo numa Geografia renovada: a Teoria Geral dos Sistemas}

Foi nos Estados Unidos que surgiu a formulação teórica que, se utilizando dessa nova possibilidade científica, mais se incorporou aos diversos campos científicos: a Teoria Geral dos Sistemas (SALES, 2004; NEVES et al., 2014). Essa teoria, proposta pelo biólogo Ludwig Von Bertalanffy, deu novos rumos às pesquisas das áreas naturais e da paisagem (voltando a se assemelhar com as sínteses naturalistas de Humboldt, Dokuchaev, etc.), que, desde a institucionalização da Geografia, seguiam o caminho da hiper-especialização, com destaque para a Geomorfologia, hipertrofiada nos estudos de Geografia Física.

A incorporação dessa teoria na Ciência Geográfica se deu, de acordo com Mendoza, Jiménez e Canteiro (2002), no - tardio — processo de renovação da geografia. Esta que, junto com as demais ciências, entrara numa crise incisiva, que colocou em cheque as suas bases epistemológicas (Geografia Tradicional).

De acordo com Moraes (1994), esse movimento de renovação não aconteceu de forma homogênea: se desenvolveu uma diversidade de propostas e de perspectivas na Geografia renovada, das quais, em função de seus propósitos, é possível agrupá-las em três grandes grupos: a Geografia Pragmática (no Brasil, “Teorética”; Geografia Quantitativa ou Nova Geografia), a Geografia Crítica (ou Radical) e a Geografia da Percepção/Comportamento. É no contexto da Pragmática que se desenvolve a Geografia Sistêmica, a qual Viktor Sotchava, Jean Tricart e Georges Bertrand, de certa forma, encabeçaram.

\section{O pioneirismo de Sotchava e a escala têmporo-espacial de Tricart: precursores imediatos}


Os estudos de Geossistemas de Sotchava consistem no primeiro emprego dessa nova concepção geográfica, já na década de 1960. Esse autor, ao que se diz, promoveu uma clara aplicação da Teoria Geral dos Sistemas (TGS) ao estudo da superfície terrestre (áreas naturais), a organizando em sistemas hierárquicos, de acordo com sua homogeneidade fisionômica e funcional (NEVES et al., 2014; CAVALCANTI, 2013), isto é, em geossistemas: "sistemas dinâmicos abertos e hierarquicamente organizados, passíveis de delimitação ou de serem circunscritos espacialmente em sua tridimensionalidade" (RODRIGUES, 2001, p. 73) e "unidade natural de todas as categorias possíveis, do geossistema planetário (envelope geográfico ou ambiente geográfico em geral) ao geossistema elementar (fácies físicogeográfica)” (SOCHAVA, 1963, p.53).

Sendo assim, Sotchava dividiu taxonomicamente o Geossistema em três ordens dimensionais (Planetária, Regional e Topológica ou Local) (GUERRA; SOUZA; LUSTOSA, 2012). Nestas, as unidades homogêneas são chamadas de "Geômeros" e unidades de estrutura diferenciada são chamadas de Geócoros. Além disso, um ponto bastante relevante levantado por Sotchava foi a prognose geográfica, um tema voltado para previsibilidade da dinâmica dos geossistemas. Antever processos dinâmicos dos geossistamas e fazer predições sobre sistemas naturais futuros são objetivos das pesquisas em Geossistemas na tradição russa. No mais, outro ponto de grande importância em sua teoria é a consideração aos aspectos econômicos e espaciais no conceito de Geossistema, dando assim uma perspectiva integradora tanto dos fenômenos naturais quanto das suas alterações antrópicas.

Apesar de bem aplicada e difundida nas repúblicas da ex-URSS, a concepção geossistêmica de Sotchava e de outros pesquisadores soviéticos não tiveram tanta repercussão no Brasil, sendo que a principal dificuldade se impôs pelas barreiras linguísticas (CAVALCANTI; CORRÊA, 2016). Com o desenvolvimento da abordagem sistêmica na Geografia e da crescente teorização da Teoria Geossistêmica, a Escola de Geografia da França passa a discutir Geossistemas, e, contemporaneamente, os grandes expoentes desta discussão são Tricart e Bertrand. Um exercendo influência sobre o outro, Tricart forneceu a escala têmporo-espacial (Cailleux e Tricart, 1956) ao sistema taxonômico de Bertrand, enquanto este, por sua vez, legou conceitos à Ecodinâmica de Tricart, de 1977. Fato é que as teorias de ambos foram (e ainda são) bem mais aplicadas e discutidas nos departamentos e periódicos de Geografia do Brasil que os trabalhos do russo Sochava (CAVALCANTI; CORRÊA, 2016).

Por exemplo, o texto Paisagem e Geografia Física Global: Esboço Metodológico, de Bertrand (1968), traduzido para o português por Olga Cruz (1972), representa um marco na Geografia Física brasileira. Tal metodologia, que reflete bem as ideias de Georges Bertrand, e suas 
respectivas mutações no decorrer do tempo são o foco de abordagem do próximo item — agora já prefaciados pelas influências diretas e indiretas que impactaram Georges Bertrand.

\section{ANÁliSE INTEGRAdA DA PAISAGEM: ESBOÇO METODOLÓGICO BERTRANDIANO}

Ao se propor analisar a paisagem, Georges Bertrand aponta, antes de tudo, que esta é uma tarefa que implica num problema de ordem epistemológica, de método. Isso porque tanto esse conceito era impreciso quanto era esquecido nos estudos da Geografia Física tradicional, que se desenvolvia sobre o assentamento do analítico e do "separativismo" (BERTRAND, 1968).

Seu primeiro passo, portanto, foi conceituar o seu objeto de estudos:

A paisagem não é a simples adição de elementos geográficos disparatados. É, em uma determinada porção do espaço, o resultado da combinação dinâmica, portanto instável, de elementos físicos, biológicos e antrópicos que reagindo dialeticamente uns sobre os outros, fazem da paisagem um conjunto único e indissociável, em perpétua evolução (BERTRAND, 1972, p. 2).

Calcado nessa definição - integrada e dinâmica — da paisagem, levando em consideração inclusive os elementos antrópicos, Bertrand procurou fazer reflexões metodológicas no sentido de conseguir apreendê-la, ao máximo possível, em sua totalidade. Nesse sentido, ele seguiu expondo sucessivamente as propostas de taxonomia, dinâmica, tipologia e cartografia das paisagens para estabelecer seu esboço metodológico — tratados a seguir.

\section{Taxonomia das paisagens (e o caso do geossistema)}

A taxonomia proposta por Georges Bertrand é dividida em seis níveis têmporo-espaciais (baseadas na escala geomorfológica têmporo-espacial de Cailleux e Tricart), que se agrupam em unidades superiores (G.I, G.II e G.III-IV) e unidades inferiores (G.IV-V, G.VI e G.VII). Assim sendo - em escala decrescente de grandeza (G.I para o G.VII) —, Zona, Domínio e Região Natural são as unidades superiores e Geossitema, Geofácie e Geótopo, as unidades inferiores (BERTRAND, 1968) - Figura 01. Nada mais são que a própria hierarquia da paisagem. 


\begin{tabular}{|c|c|c|c|c|c|c|c|}
\hline \multirow{2}{*}{$\begin{array}{c}\text { UNIDADES DA } \\
\text { PAISAGEM }\end{array}$} & \multirow[b]{2}{*}{$\begin{array}{c}\text { ESCALA } \\
\text { TEMPORO- } \\
\text { ESPACIAL (A. } \\
\text { CAILEUX J. } \\
\text { TRICART) }\end{array}$} & \multirow{2}{*}{$\begin{array}{l}\text { EXEMPLO TOMADO NUMA } \\
\text { MESMA SÉRIE DE } \\
\text { PAISAGEM }\end{array}$} & \multicolumn{5}{|c|}{ UNIDADES ELEMENTARES } \\
\hline & & & RELEVo (1) & Clima (2) & BOTÂNICA & BIOGEOGRAFIA & $\begin{array}{c}\text { UNIDADE } \\
\text { TRABALHADA } \\
\text { PELO HOMEM } \\
\text { (3) }\end{array}$ \\
\hline ZONA & $\begin{array}{c}\text { G I grandeza } \\
\text { G. I }\end{array}$ & Temperada & & Zonal & & Bioma & Zona \\
\hline DOMÍNIO & G. II & Cantábrico & $\begin{array}{l}\text { Domínio } \\
\text { estrutural }\end{array}$ & Regional & & & $\begin{array}{c}\text { Domínio } \\
\text { Região }\end{array}$ \\
\hline $\begin{array}{c}\text { REGIÃO } \\
\text { NATURAL }\end{array}$ & G. III-IV & Picos da Europa & $\begin{array}{l}\text { Região } \\
\text { estrutural }\end{array}$ & & $\begin{array}{l}\text { Andar } \\
\text { Série }\end{array}$ & & $\begin{array}{l}\text { Quarteirão rural } \\
\text { ou urbano }\end{array}$ \\
\hline GEOSSISTEMA & G. IV-V & $\begin{array}{c}\text { Atlântico Montanhês } \\
\text { (calcário sombreado com } \\
\text { faia higrófila a Asperula } \\
\text { odorata em "terra fusca") }\end{array}$ & $\begin{array}{l}\text { Unidade } \\
\text { estrutural }\end{array}$ & local & & $\begin{array}{c}\text { Zona } \\
\text { equipotencial }\end{array}$ & \\
\hline GEOFÁCIES & G. VI & $\begin{array}{c}\text { Prado de ceifa com } \\
\text { Molinio-Arrhenatheretea } \\
\text { em solo lixiviado } \\
\text { hidromórfico formado em } \\
\text { depósito morâinico }\end{array}$ & & & $\begin{array}{c}\text { Estádio } \\
\text { Agrupamen- } \\
\text { to }\end{array}$ & & $\begin{array}{l}\text { Exploração ou } \\
\text { quarteirão } \\
\text { parcelado } \\
\text { (pequena ilha } \\
\text { ou cidade) }\end{array}$ \\
\hline GEÓTOPO & G. VII & $\begin{array}{l}\text { "Lapiés" de dissolução } \\
\text { com Aspidium lonchitis } \\
\text { em microsolo úmido } \\
\text { carbonatado em bolsas }\end{array}$ & & Microclima & & $\begin{array}{c}\text { Biótopo } \\
\text { Biocenose }\end{array}$ & $\begin{array}{l}\text { Parcela (casa } \\
\text { em cidade) }\end{array}$ \\
\hline
\end{tabular}

NOTA: As correspondências entre as unidades são muito aproximadas e dadas somente a título de exemplo.

1 - conforme A. Cailleux, J. Tricart e G. Viers; 2 - conforme M. Sorre; 3 - conforme R. Brunet.

Figura 01. Unidades taxonômicas propostas por G. Bertrand em 1968. Fonte: Bertrand (1968).

Essa taxonomia permite identificar, nas unidades inferiores, a relação entre o Potencial Ecológico (geomorfologia, clima e hidrologia), Exploração Biológica (vegetação, solo e fauna) e Ação Antrópica (ação humana). Nas superiores, a unidade "Zona" seria defina pelos climas zonais e os biomas, a unidade "Domínio" pela combinação do relevo com climas oceânicos e a "Região Natural” pela estrutura do relevo combinado com a vegetação (BERTRAND; BERTRAND, 2009).

O Geossistema, para Bertrand (1968), ao contrário da conceituação genérica e totalizadora de Sotchava (1963), tem dimensões espaciais bem definidas (G.IV-V) - compreendidas entre alguns quilômetros quadrados até algumas centenas de quilômetros quadrados $-\mathrm{e}$ é aquele que mais importa ao geógrafo, por apresentar uma equiparação dinâmica entre o Potencial Ecológico, a Exploração Biológica e a Ação Antrópica (Figura 02) - essa última com possibilidade de concorrência com as outras duas devido ao geossistema se encontrar numa escala têmporo-espacial compatível com a escala humana (DINIZ; OLIVEIRA; BERNARDINO, 2015). Essa concepção de Geossistema de Bertrand é um dos principais pontos que diferenciava suas formulações teóricometodológicas das do russo Sotchava (CAVALCANTI, 2013). 


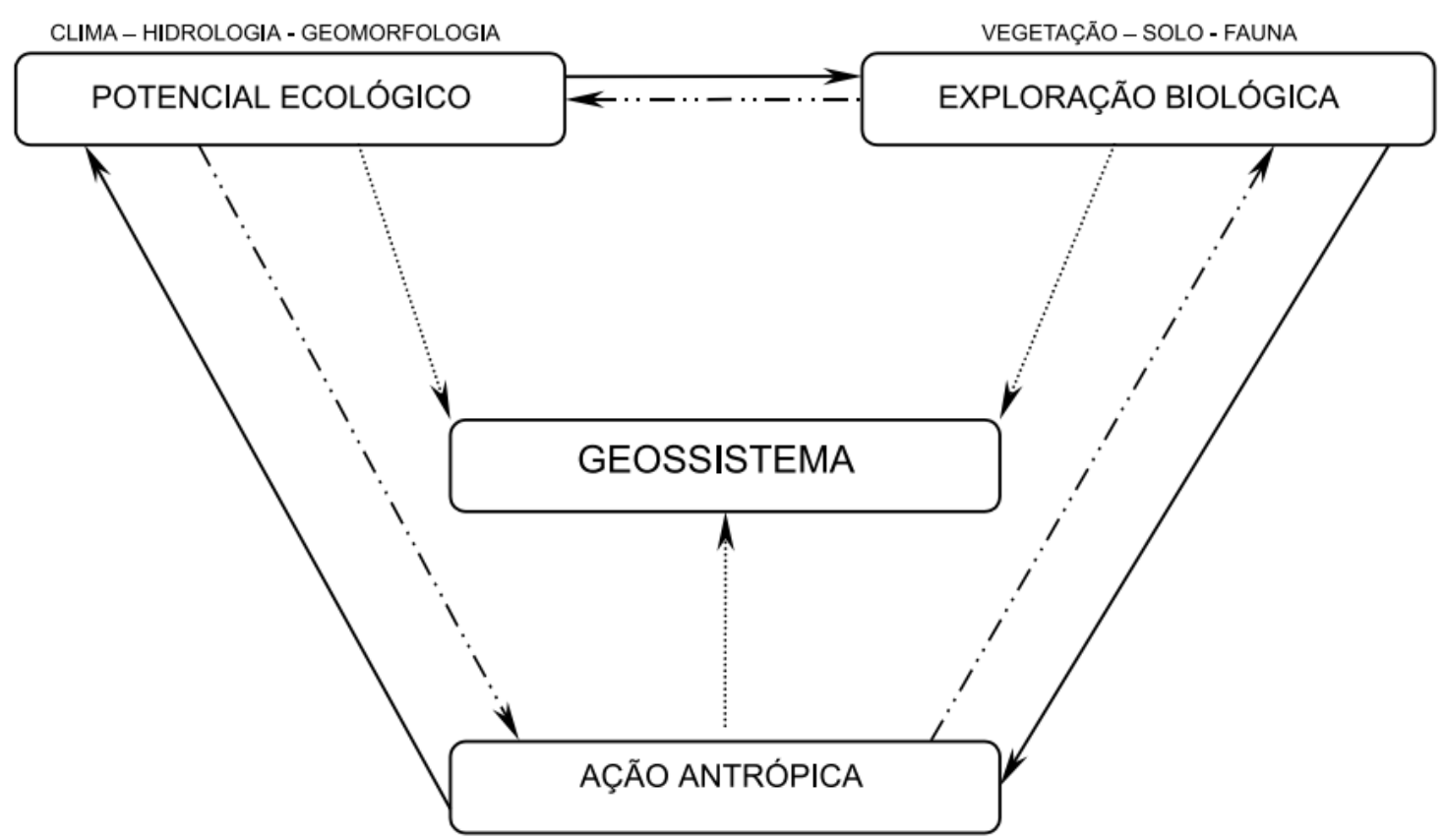

Figura 02. Geossistema, segundo Bertrand (1968). Fonte: Bertrand (1968).

No entanto, isso muda quando Bertrand passa a escrever artigos com o georgiano Nikolai L. Beruchashvili (CAVALCANTI, 2013). Numa nova concepção, em 1978, o autor uniformitariza o significado do termo geossistema àquele empregado por Sotchava:

Em 1964-1965, nós havíamos definido o geossistema como uma unidade taxoxorológica entre outras (geótopo - geofácies - geossistema - região natural domínio geográfico - zona). O geossistema representava um espaço natural homogêneo dividido em geofácies. (...) Num esforço de uniformização conceitual e de simplificação da linguagem, nós, entretanto, estamos de acordo, com a definição mais lógica de V.B. Sochava, que faz do geossistema, como do ecossistema, uma abstração e um conceito (BEROUTCHACHVILI; BERTRAND apud CAVALCANTI, 2013, p. 81, tradução do autor).

Ainda depois, Georges Bertrand vai novamente mudar seu entendimento sobre geossistema, reduzindo-o a uma das três dimensões do sistema tripolar Geossistema-Território-Paisagem, que representa, por sua vez, os três polos do sistema ambiental (ou meio ambiente) (BERTRAND; BERTRAND, 2009) - o que será abordado mais adiante.

\section{A dinâmica da paisagem}

Georges Bertrand, ao considerar a paisagem como uma entidade global, também admite que os componentes que a integram participam de uma mesma dinâmica. Portanto, a dinâmica da paisagem não é a evolução individual dos elementos que a compõem, mas, sim, uma evolução pela interação entre todos os seus elementos, que se reproduzem tridimensionalmente em um estado 
(BERTRAND, 1968). E isso exige que os geógrafos compreendam os mecanismos gerais da paisagem, especialmente nos geossistemas e geofácies. No entanto, Bertrand (1968) deixa uma carência metodológica quanto a este item levantado.

No mais, ele indica que a predominância de um determinado elemento é que irá individualizar e caracterizar os sistemas, sendo passíveis de serem classificados a partir deste critério. No caso desse esboço metodológico, Bertrand propõe apenas duas classes para os sistemas de evolução das paisagens - os sistemas geomorfológicos e os antrópicos —, sinalizando que existem ainda outros tipos (DINIZ; OLIVEIRA; BERNARDINO, 2015).

\section{Tipologia das paisagens}

No intuito de intitular as unidades de paisagem, especialmente os geossistemas (G.IV-V), Bertrand (1968), inspirado na teoria de bioresistasia de H. Erhart, propõe uma "tipologia dinâmica", que as classifica segundo sua evolução - o que, conforme ele, também engloba, consequentemente, a fisionomia paisagística, uma vez que a situação vegetal representa a síntese dos diversos processos que ocorrem no meio. Esse procedimento de cognominação leva em conta três elementos: o sistema de evolução, o estágio atingido em relação ao "clímax" e o sentido geral da dinâmica (progressiva, regressiva, estabilidade) (BERTRAND, 1968). Assim, Bertrand (1968) modelizou em 6 tipos de geossistemas reagrupados em 2 conjuntos dinâmicos diferentes, os quais estão sistematizados no Quadro 1.

Quadro 1. Sistematização da Tipologia de Paisagens de Bertrand (1968). ${ }^{3}$ Fonte: elaborado pelos autores com base em Bertrand (1968, p. 149-150).

\begin{tabular}{|c|c|}
\hline CONJUNTOS & TIPOS \\
\hline \multirow{4}{*}{$\begin{array}{l}\text { Os geosistemas em biostasia - trata-se de paisagens onde a } \\
\text { atividade geomorfogenética é fraca ou nula. O potencial ecológico } \\
\text { é, no caso, mais ou menos estável. O sistema de evolução é } \\
\text { dominado pelos agentes e os processos bio-químicos: pedogênese, } \\
\text { concorrência entre as espécies vegetais, etc. }\end{array}$} & $\begin{array}{l}\text { a) Geossistemas climácicos, } \\
\text { plésioclimácicos ou } \\
\text { subclimácicos. }\end{array}$ \\
\hline & $\begin{array}{l}\text { b) Geossistemas } \\
\text { paraclimácicos. }\end{array}$ \\
\hline & $\begin{array}{l}\text { c) Geossistemas degradados } \\
\text { com dinâmica progressiva. }\end{array}$ \\
\hline & $\begin{array}{l}\text { d) Geossistemas degradados } \\
\text { com dinâmica regressiva sem } \\
\text { modificação importante do } \\
\text { potencial ecológico. }\end{array}$ \\
\hline $\begin{array}{l}\text { Os geosistemas em resistasia }- \text { A geomorfogênese domina a } \\
\text { dinâmica global das paisagens. A erosão, o transporte e a }\end{array}$ & $\begin{array}{l}\text { a) Geossistemas com } \\
\text { geomorfogênese natural. }\end{array}$ \\
\hline
\end{tabular}

\footnotetext{
${ }^{3}$ C.f. Bertrand (1968) e Diniz, Oliveira e Bernardino (2015) para buscar informações sobre o significado de cada tipo.
} 
acumulação dos detritos de toda a sorte levam a uma mobilidade das vertentes e a uma modificação mais ou menos possante do potencial ecológico. A geomorfogênese contraria a pedogênese e a colonização vegetal. b) Geossistemas regressivos com geomorfogênese ligada à ação antrópica.

\section{Cartografia das paisagens}

Num último item de seu esboço metodológico (1968), Georges Bertrand tratou da representação cartográfica das paisagens. Afirmou que essa deve ocorrer, assim como os diversos levantamentos que a precedem (geomorfológicos, pedológicos e fitogeográficos, exame das águas superficiais, observações meteorológicas elementares, inquéritos sobre o sistema de valorização econômica), orientados sob a escolha de uma linha mestra escalar.

Nesse sentido, Bertrand (1968), apontando que a análise deve descer ao menos no nível dos geofácies e endossando a possibilidade disso a partir de fotografias aéreas, propõe escalas de análise padronizadas para os geossistemas (G.IV-V) e os geofácies (G.VI) e sistemas de representação cartográfica temática para essas unidades de paisagem.

Para os geossistemas, estipula:

Na escala média (1/100.000 e 1/200.000) pode-se cartografar os geosistemas de maneira satisfatória com a condição de renunciar à acumulação dos sinais analíticos e de escolher uma representação sintética. Cada geosistema corresponde a um lugar cuja cor e respectiva trama são escolhidas em função da dinâmica do geosistema, (exemplo: azul para os geosistemas climácicos, verde para os geosistemas paraclimácicos, amarelo para os geosistemas regressivos com degradação antrópica dominante, vermelho para os geosistemas com evolução essencialmente geomorfológica) (BERTRAND, 1972, p. 151).

Para os geofácies, sugere da mesma forma:

$\mathrm{Na}$ escala grande $1 / 20.000$, pode-se facilmente cartografar os geofácies no interior dos geosistemas. A cor ou a variação na cor de cada geosistemas indica a situação dinâmica em relação ao clímax (geofácies climax em azul, geofácies degradado em amarelo ou em vermelho). Pode-se assim escolher um tema, por exemplo, como as relações entre a cobertura vegetal e a erosão "epidérmica" (BERTRAND, 1972, p. 151).

Portanto, nessa obra de 1968, "Paysage et géographie physique globale: Esquisse méthodologique", Georges Bertrand nos apresenta uma direção metodológica concisa para a descrição, explicação e classificação científica das paisagens. Estabelecendo uma possibilidade real de apreensão da paisagem segundo a integração e a interdisciplinaridade. 
No entanto, ao mesmo tempo em que se propagou por várias escolas geográficas, essa formulação teórico-metodológica também recebeu, proporcionalmente, duras críticas, que culminaram em relevantes mudanças ideológicas do próprio autor e em adaptações no esboço metodológico inicialmente proposto - neste último caso, realizado por outros autores.

\section{CRÍticAs E PROPOSIÇÕES À ANÁliSE DA PAISAGEM DE BERTRAND: O PIONEIRISMO PRÓPRIO: GTP - GEOSSISTEMA-TERRITÓRIO-PAISAGEM}

As críticas à Análise Integrada da Paisagem de Bertrand (1968) tiveram como principais escopos as dimensões espaciais e temporais dessa metodologia (CAVALCANTI; CORRÊA, 2016). $\mathrm{Na}$ perspectiva de Sales (2004), a abordagem sistêmica da paisagem pouco contemplou a perspectiva temporal dos processos que ocorrem na paisagem e nas unidades taxonômicas da paisagem; em detrimento da consideração cronológica, muitos estudos se detém à simples descrição das unidades da paisagem.

É importante salientar que as críticas quanto à cronologia são cabíveis para a abordagem elaborada por Bertrand, e que não devem ser generalizadas para a Teoria Geossistêmica, pois na perspectiva de Sotchava foi possível estudar os processos atuantes na paisagem, uma vez que o extenso conjunto de estações de coleta de dados distribuídos pelo território da ex-URSS permitiu estudar e monitorar os processos (CAVALCANTI; CORRÊA, 2016) - e aí reside mais uma diferença entre Sotchava (1977) e Bertrand (1968).

Já no tocante aos assuntos de espacialidade, a proposta de Georges Bertrand foi criticada em virtude de considerar, para uma abordagem global, escalas que foram elaboradas em território francês. O que difere das que foram propostas por Sotchava, uma vez que na perspectiva do geógrafo soviético, um geossistema poderia ter dimensões variantes (Planetária, Regional e Local) segundo sua classificação (TROPPMAIR; GALINA, 2006).

Uma importante crítica feita à proposta de Georges Bertrand foi quanto à inserção do homem na análise sistêmica, sendo que o papel feito por este se limitou a somente um elemento exploratório da paisagem, mera ocupação do homem nas unidades taxonômicas inferiores. A presença do homem vai muito além da "ação antrópica", e ele, enquanto organizado em sociedade, é um agente organizador do espaço (GUERRA; SOUZA; LUSTOSA, 2012).

Em virtude dessas e de diversas outras críticas direcionadas a sua primeira proposta, atrelada à crescente influência das correntes Crítica e Cultural no âmbito da Geografia, a abordagem integrada de Bertrand ganha novos atributos, inclusive com uma mudança de caráter epistemológico. 
Decorre daí uma nova proposta teórica do autor: a abordagem Geossistema - Território Paisagem (GTP). A nova abordagem passa a ser holística, diagonal e transversal. Agora, não partindo mais da paisagem, e, sim, da tríade Geossistema - Território - Paisagem (GUERRA; SOUZA; LUSTOSA, 2012). Nessa abordagem, o Geossistema passa a ser a fonte, as características bio-físico-químico de uma porção de terras; o Território seria o recurso, o sócio-econômico; já a Paisagem, a identidade, o cultural, o simbólico - figura 03. Dessa forma, a análise sob o ponto de vista do GTP é tridimensional, sendo três espaços e três tempos (BERTRAND; BERTRAND, 2009).

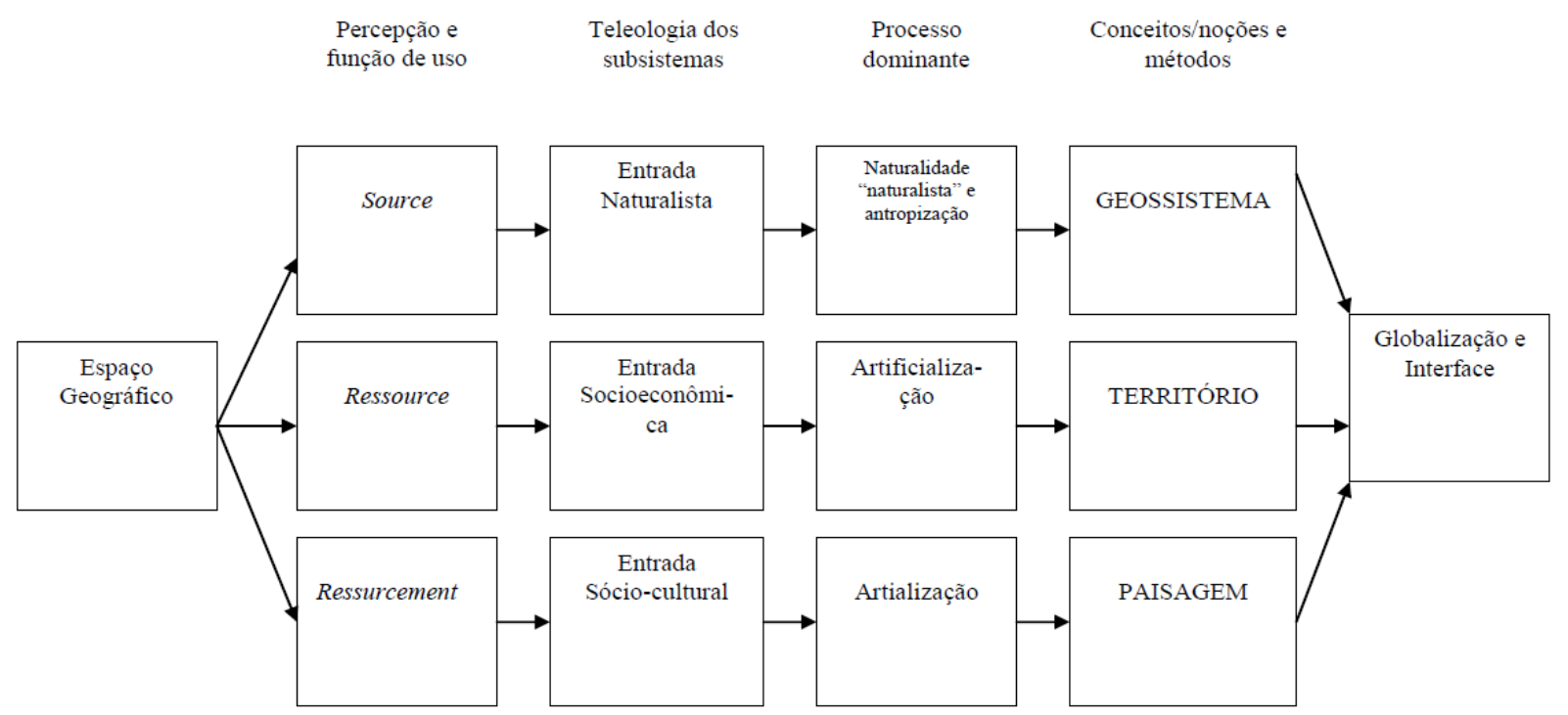

Figura 03. Principais elementos dos três tempos do GTP. Fonte: Guerra, Souza e Lustosa (2012).

Um aspecto que deve ganhar relevo nesta etapa do artigo é a nítida guinada das concepções e dos trabalhos de Georges Bertrand ao método fenomenológico, em detrimento do, até então utilizado, método indutivo, o que se deveu à aproximação do autor ao universo teóricometodológico da Geografia Humanista e Cultural. É perceptível que a abordagem GTP evidencia o pertencimento ao lugar, os aspectos culturais, as relações de poder e os modos como estes elementos se dão nos sistemas naturais (NEVES et al., 2014).

\section{Apropriação e incorporações ao esboço metodológico de Bertrand (1968): alguns exemplos}

Devido ao abandono, por parte de Georges Bertrand, à sua concepção teórico-metodológica inicial, outros pesquisadores tomaram a iniciativa de tentar trazer elementos novos para o seu esboço metodológico. Nesse sentido, teorias de outros autores consagrados - como Tricart e o próprio Sotchava - foram incorporados às concepções iniciais de Bertrand; além de concepções dos 
próprios pesquisadores dispostos a utilizá-las e difundi-las. É nesse contexto em que estão inseridos os trabalhos de Bolós (1981), Souza (2000) e, recentemente, Diniz, Oliveira e Bernardino (2015).

Bolós (1981) foi uma das grandes reprodutoras da Geografia Física bertrandiana (DINIZ; OLIVEIRA; BERNARDINO, 2015). Estabeleceu avanços significativos quanto à noção de tempo, dinâmica e evolução das paisagens. Evidenciando-se, principalmente, pela incorporação da concepção de dinâmica temporal das paisagens às concepções Bertrandnianas.

Souza (2000), por sua vez, em seus trabalhos aplicados ao estado do Ceará, Brasil, tem adaptado a visão geossistêmica de Sotchava, a ecodinâmica de Tricart e a taxonomia da paisagem de Bertrand aos estudos do semiárido brasileiro (DINIZ; OLIVEIRA; BERNARDINO, 2015). O que deu vazão para a Proposta de classificação das paisagens integradas, de Diniz, Oliveira e Bernardino (2015).

Assim como fez Ab’Saber, que constituiu os Domínios Morfoclimáticos Brasileiros a partir do diálogo entre, pelo menos, três modelos conceituais (CAVALCANTI, 2013), Diniz, Oliveira e Bernardino (2015) imaginam a possibilidade de uma análise integrada da paisagem mais completa a partir, também, de três embasamentos teórico-metodológicos: de Bertrand (1968), Tricart (1977) e Bolós (1981) (Cf. DINIZ; OLIVEIRA; BERNARDINO, 2015). E assim propõem uma metodologia de classificação de paisagens semiáridas no Brasil, tomando como base as concepções bertrandianas, mas promovendo adaptações e inserções nesse esboço metodológico.

\section{CONSIDERAÇÕES FINAIS}

A paisagem representa um importante conceito na Ciência Geográfica. Por isso, entendê-la envolve compreender as diferentes definições, estudos e reflexões que a tiveram como alvo. Nesse sentido, é que este artigo procurou interpretar a análise desse objeto de estudos sob a ótica da abordagem integrada de Georges Bertrand (1968).

Foi possível compreender que as concepções desse autor não são únicas, mas, sim, um resultado de um processo evolutivo de acumulação de pensamentos holísticos sobre áreas naturais. Isso envolve, então, todo um contexto progressivo de desenvolvimento de sínteses naturalistas, que, até certo ponto, ocorreu em contra-corrente ao contexto de especialização das ciências; o que veio a se modificar no século XX, quando uma ebulição de acontecimentos suscitou imponentes mudanças de paradigmas sobre a apreensão da realidade geográfica.

Assim, considerando o pensamento Bertrandniano de 1968 e o contexto em que a Geografia estava inserida nesse momento, partimos para a efetiva revisão das proposições elencadas por esse autor. 
A paisagem foi conceituada, no texto Paisagem e Geografia Física: esboço metodológico (1968), como um conjunto único, indissociável e em perpétua evolução. Isso exigiu de Bertrand a elaboração de uma formulação teórico-metodológica - que ele menciona ser somente um esboço metodológico - que pudesse apreendê-la enquanto essa totalidade - como próprio conceitua. Portanto, nesse seu trabalho foi apresentado, sucessivamente, apontamentos sobre a taxonomia, dinâmica, tipologia e cartografia das paisagens.

Essas considerações foram tidas como um marco nos estudos de Geografia Física, e exerceu grande influência no âmbito da brasileira, ainda mais que os estudos de geossistemas de Sotchava (1977).

No entanto, a Análise Integrada da Paisagem colocada por Bertrand (1968) não se estabeleceu como um elo final dos estudos integrados da superfície terrestre hierarquizada. Pelo contrário, como muito aponta o próprio autor, essa obra foi tão somente um esboço metodológico. Por esse fato, recebeu duras críticas e adaptações, o que culminou até numa radical mudança epistemológica e ideológica de Bertrand (1968).

Todos esses pontos estão aqui tratados a fim de que esse estudo revisional efetivamente contribua na inserção das concepções sobre a paisagem nas novas gerações geográficas.

\section{AGRADECIMENTOS}

O presente trabalho foi realizado com apoio da Coordenação de Aperfeiçoamento de Pessoal de Nível Superior - Brasil (CAPES) - Código de Financiamento 001. Agradecemos o apoio financeiro supracitado, assim como os institucionais e de infraestrutura: à Universidade Federal do Rio Grande do Norte - UFRN; ao Programa de Pós-Graduação e Pesquisa em Geografia - PPGe; ao Centro de Ciências Humanas, Letras e Artes - CCHLA; ao Centro de Ensino Superior do Seridó CERES; e aos laboratórios: Laboratório de Geoprocessamento e Geografia Física - LAGGEF e Laboratório de Biogeografia - LABIGEO.

\section{REFERÊNCIAS}

BERTRAND, G. Paysage et géographie physique globale: esquisse méthodologique. Revue géographique des Pyrénées et sud-ouest, v. 39, fasc. 3, 1968. p. 249-272.

BERTRAND, G. Paisagem e Geografia Física Global: esboço metodológico. Cruz, Olga (trad.). Cadernos de Ciências da Terra. São Paulo, USP-IGEOG, nº 43, 1972.

BERTRAND, C.; BERTRAND, G. Uma geografia transversal e de travessias: o meio ambiente através dos territórios e das temporalidades. Maringá: Ed. Massoni, 2009. p. 29-56; 304-345. 
CAVAlCANTI, L. C. S. Da Descrição de Áreas à Teoria dos Geossistemas: uma Abordagem Epistemológica sobre Sínteses Naturalistas. Tese (Doutorado em Geografia). Recife: UFPE. 2013. $217 \mathrm{p}$.

CAVALCANTI, L. C. S.; CORRÊA, A. C. B. Da descrição de áreas às sínteses naturalistas: uma abordagem historiográfica sobre a ideia de ‘áreas naturais'. Espaço \& Geografia, v.17, n. 2, p. 377 422, 2014.

CAVAlCANTI, L. C. S.; CORRÊA, A. C B. Geossistemas e Geografia no Brasil. Revista Brasileira de Geografia, v. 61, n. 02, p. 3-33, 2016.

CHRISTOFOLETTI, A. Modelagem de sistemas ambientais. São Paulo: Blucher, 1999. p. 1-18.

BOLÓS, M. I. C. Problemática actual de los estudios de paisaje integrado. Revista de geografía, v. 15, n. 1, p. 45-68, 1981.

DINIZ, M. T. M.; OLIVEIRA, G. P.; BERNARDINO, D. S. M. Proposta de classificação das paisagens integradas. Revista de Geociências do Nordeste, v.1, n.1, p.50-65, 2015.

FERREIRA, C. C.; SIMÕES, N. N. A evolução do pensamento geográfico. Lisboa: Gradiva, 1986.

FIGUEIREDO, N. Da importância dos artigos de revisão da literatura. R. bras. Biblioteconomia e Documentação. v. 23, p. 131-135, 1990.

GUERRA, M. D. F.; SOUZA, M. J. N.; LUSTOSA, J. P. G. Revisitando a Teoria Geossistêmica de Bertrand no século XXI: aportes para o GTP (?). Geografia em questão, v. 05, n. 02, 2012.

NASCIMENTO, A. L. A evolução do Conhecimento Geográfico: da antiguidade à era da globalização. Maceió: Edufal, 2003.

NEVES, C. E.; MACHADO, M.; HIRATA, C. A.; STIPP, N. A. F. A importância dos geossistemas na pesquisa geográfica: uma análise a partir da correlação com o ecossistema. Revista Sociedade \& Natureza, v. 26, n. 02, 2014.

MENDONÇA, F. Geografia física: ciência humana? São Paulo: Contexto, 1996. 72 p.

MENDONÇA, F. Geografia socioambiental. Terra Livre, v. 1, n. 16, p. 113-132, 2015.

MENDOZA, J. G.; JIMÉNEZ, J. M.; CANTEIRO, N. O. El pensamiento geografico. Alianza Editorial: Madrid, 2002. p. 96-194.

MORAES, A. C. R. Geografia: Pequena Historia Critica. São Paulo: Hucitec, 1994.

ODUM, E. P. Ecologia. Rio de Janeiro: Guanabara Koogan, 2012. p. 09-60.

RODRIGUES, C. A teoria geossistêmica e sua contribuição aos estudos geográficos e ambientais. São Paulo, Revista do Departamento de Geografia - USP, 14, 2001. 
SALES, V. C. Geografia, sistemas e análise ambiental: abordagem crítica. GEOUSP-espaço e tempo, $\mathrm{n}^{\circ}$ 16, p. 125 - 141, 2004.

SOCHAVA, V.B. Algumas noções e termos da Geografia Física. Relatórios do instituto de Geografia da Sibéria e do Extremo Oriente. 3. 1963. p.53.

SOCHAVA, V. B. O estudo de geossistemas. Métodos em questão, n.16, p. 01-51, 1977.

SOUZA, J. C. O. Análise Geossistemica na Bacia Hidrográfica do Rio São Miguel, Alagoas: Estudo e Interpretação de Paisagens Hidrogeomorfológicas. Revista Brasileira de Geografia Física, v. 7, n. 5, p. 880-890, 2015.

SOUZA, M. J. N. Bases Naturais e Esboço do Zoneamento Geoambiental do Estado do Ceará. In: LIMA, L. C., SOUZA, M. J. N., MORAIS, J. O. Compartimentação Territorial e Gestão Regional do Ceará. Fortaleza, Funece, 2000.

TRICART, J. Ecodinâmica. Rio de Janeiro, FIBGE-SUPREN, 1977.

TROPPMAIR, H.; GALINA, M. H. Geossistemas. Mercator, v. 05, n 10, p. 79-89, 2006.

Recebido em: 15/06/2018

Aceito para publicação em: 29/07/2018 